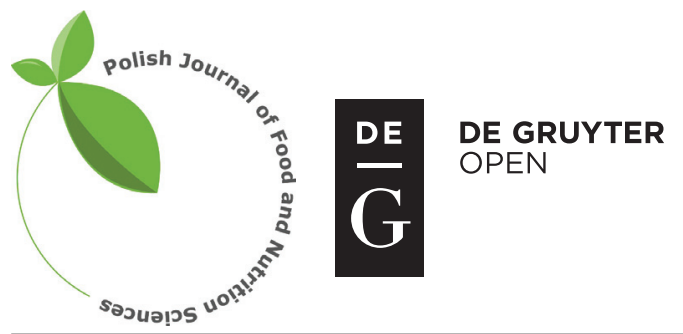

Pol. J. Food Nutr. Sci., 2018, Vol. 68, No. 3, pp. 273-280

DOI: $10.1515 /$ pjfns-2018-0006 http://journal.pan.olsztyn.pl

Original research article

Section: Food Technology

\title{
Encapsulation of Gallic Acid with Acid-Modified Low Dextrose Equivalent Potato Starch Using Spray- and Freeze-Drying Techniques
}

\author{
Igor Sepelevs ${ }^{1 *}$, Valentina Stepanova ${ }^{2}$, Ruta Galoburda ${ }^{1}$ \\ ${ }^{1}$ Faculty of Food Technology, Latvia University of Agriculture, Rigas 22, LV-3004, Jelgava, Latvia \\ ${ }^{2}$ Faculty of Material Science and Applied Chemistry, Institute of General Chemical Engineering, \\ Riga Technical University, Pulka 3, LV-1007, Riga, Latvia
}

Key words: encapsulation, freeze-drying, spray-drying, gallic acid

The main objective of the present study was to investigate the effect of spray- and freeze-drying techniques on the microencapsulation of a gallic acid compound using the acid-hydrolyzed low dextrose equivalent potato starch as a wall material. During the experiment, it was possible to achieve encapsulation efficiency of $70-84 \%$ for the freeze-dried and $65-79 \%$ for spray-dried samples, without statistically significant difference $(P>0.05)$ in the encapsulation efficiency between the mentioned methods. Spray-dried samples formed spherical capsules with a higher number of micropores. Meanwhile, freeze-dried samples were shapeless, exposed larger pore volume (from $2.4 \times 10^{-3}$ to $9.5 \times 10^{-3} \mathrm{~cm}^{3} / \mathrm{g}$ against $1.2 \times 10^{-3} 4.9 \times 10^{-3} \mathrm{~cm}^{3} / \mathrm{g}$; analyzed by Barrett-Joyner-Halenda method) and overall higher surface area $\left(0.632-1.225 \mathrm{~m}^{2} / \mathrm{g}\right.$ against $0.472-1.296 \mathrm{~m}^{2} / \mathrm{g}$; analyzed by Barrett-Joyner-Halenda method). Due to this fact, more gallic acid molecules were exposed to environmental factors and can be counted as losses. In addition, freeze-dried samples demonstrated lower water activity than spray-dried samples $(0.075 \pm 0.014$ against $0.178 \pm 0.008)$. Results showed that it is not practical to use freeze-drying for modelling encapsulation for food industry without a special necessity for protection of easily degradable chemical compounds. The present work makes a basis for the future studies of the microencapsulated phenolics application in food production.

\section{INTRODUCTION}

Food enrichment with biologically active compounds is an important part of the modern healthy lifestyle trends in food production and consumption. To provide the positive effect on human health, active compounds (either vitamin, phenolics, polyunsaturated fatty acid, or etc.) due to their sensitivity to the environmental impacts must be protected against degradation till they reach targeted food product or human gastrointestinal tract, depending on the application purposes.

Six reasons for encapsulation in the food industry were distinguished: a) to minimize the core reactivity with the environment, b) to control the transfer rate of the core material to the outside environment, c) to make transportation and handling easier, d) to control the release rate of the core material, e) to hide the core taste of the core, and f) to dilute the core material if it is required to be used in very small amounts [Shahidi \& Hax, 1993]

Natural phenolic compounds attract attention due to their health benefits [Im et al., 2008; Pourcel et al., 2007; Singh et al., 2008] but some of them are astringent and bitter that makes phenolics application more complex. One of the possible solutions, that can provide phenolics protection from the environment and mask their sensory properties, is to

\footnotetext{
*Corresponding Author: E-mail: igor_shepelev@inbox.lv amount for drying purposes. As emulsifying properties of wall

make a protective shell around them. Encapsulation is a process in which solid particles or liquid droplets are surrounded by a coating or embedded in a homogenous or heterogeneous matrix. Capsule particles, that range in size from one micron to few millimeters, usually are called microcapsules and encapsulation process - microencapsulation [Dubey et al., 2009].

There are restrictions according to the wall material that can be used in the food industry, as it must be a food grade, exhibit low viscosity at high concentrations for easy pumping and faster drying, non-reactive with encapsulated material and environment. If wall and core materials have different polarities, the wall material should exhibit good emulsifying properties to form a good film. Most commonly used are gum arabic, modified starches and maltodextrins (hydrolyzed starches), whey protein, sodium caseinate and gelatin [Loksuwan, 2007]. Gum arabic is one of the most preferred wall materials, because it is a natural plant polysaccharide, makes stable emulsions and has a good volatile retention, but, due to its low production yield, it is expensive and not easily accessible. Modified starches are similar to gum arabic by their functional properties, are inexpensive and broadly available [Varavinit, 2001]. Both, gum arabic and modified starches, exhibit low viscosity at high concentrations. High viscosity complicates mixture pumping, as high solid content in the wall-core material mixtures is desirable because it decreases necessary energy 
material are irrelevant in the case of hydrophilic compound encapsulation in the hydrophilic matrix, starch hydrolysates (maltodextrin) will be used in the present study. Maltodextrins are available in dextrose equivalent (DE; indicates the degree of hydrolysis) ranging from 2 to 36.5 and offer good protection against oxidation, but do not possess emulsifying properties and because of that are combined with other two mentioned materials, if necessary [Reineccius, 1989; Poshadri \& Kuna, 2010]. Meanwhile, emulsifying starches exhibit poor flavor protection against oxidation and have off flavor [Inglett et al., 1988]. Many studies reported positive results of applying hydrolyzed starches in combination with other wall materials or emulsifying agents [Barbosa et al., 2005; Carneiro et al., 2013; Mulcahy et al., 2016]. However, it was shown that hydrolyzed starch with low dextrose equivalent can be used to produce microcapsules that provide good retention of hydrophobic $\beta$-carotene during drying process and show overall better microencapsulation efficiency than native starch does [Loksuwan, 2007].

There are various microencapsulation technologies that can be used for the food production, with spray-drying (SD) as the most common in the food industry. It is an economical and effective method for protecting materials [Poshadri \& Kuna, 2010]. Material for encapsulation is homogenized with the carrier material, usually at a ratio of 1:4. Then, the acquired mixture is fed into a spray dryer, where it is atomized and dried in the hot air stream [Gibbs, 1999; Poshadri \& Kuna, 2010]. Atomized droplets tend to form spherical globules that tend to increase surface area to mass ratio. As SD applies high temperatures, heat-sensitive core materials can be damaged. An alternative simple technique, that in opposite uses very low temperatures, is freeze-drying (FD), that is currently used for the dehydration of almost all heat-sensitive materials. It is a simple technique. Core and wall material mixture is frozen and freeze-dried. It is necessary to keep in mind that the chosen matrix material will determine retention of volatile compounds during the freeze-drying. Dry material can be crushed to produce a powder with uneven shape particles [Dubey et al., 2009; Kopelman et al., 1977; Poshadri \& Kuna, 2010].

The present article is addressing the fact that freeze-drying is often used during scientific investigations even for the stable compound encapsulation - which is a costly and energy-consuming method, which makes the produced capsules too expensive for the application in the food industry. In comparison to SD, FD can be more than 4 times as expensive depending on the parameters and dried substance [Flink, 1977]. The main objective of the present study was to investigate and evaluate the applications of SD and FD techniques for the microencapsulation of gallic acid (GA) using the acid-hydrolyzed low dextrose equivalent potato starch as a wall material.

\section{MATERIALS AND METHODS}

\section{Chemicals and reagents}

Potato starch was purchased from Aloja Starkelsen (Ungurpils, Latvia); ethanol (96.6\%) from Stumbras (Kaunas, Lithuania); Folin-Ciocalteu phenol reagent and sodium car- bonate from Merck (Darmstadt, Germany); while acetic acid, sulfuric acid, copper sulfate pentahydrate, potassium sodium tartrate tetrahydrate, sodium hydroxide, gallic acid (GA, 98\%), and D-(+)-glucose analytical standard from SigmaAldrich (Riga, Latvia).

\section{Acidic modification of potato starch}

Acid modified potato starch was prepared according to the Thailand Patent No. 2146 method [Loksuwan, 2005] with slight modifications. Briefly, potato starch was mixed with $3 \mathrm{~N}$ sulfuric acid in the ratio of 1:5 (w/v). The mixture was stirred magnetically at $60^{\circ} \mathrm{C}$ for $3 \mathrm{~h}$. After hydrolysis, the remaining acid was neutralized with saturated sodium carbonate. The starch slurry was placed in the CM-6MT centrifuge (Elmi Ltd., Riga, Latvia) at $2500 \times$ g for 5 min and supernatant was removed. Then, starch was washed with triple volumes of distilled water, followed with ethanol, and was then dried at $70^{\circ} \mathrm{C}$ overnight. The dried starch was ground in a KN 195 Knifetec laboratory mill (Foss, Hilleroed, Denmark).

Dextrose equivalent of the obtained modified starch was determined using the Lane \& Eynon [1923] titration method.

\section{Sample preparation}

Prior to encapsulation, the modified starch was suspended in distilled water $(20 \mathrm{~g} / 100 \mathrm{~g})$ and heated at $120^{\circ} \mathrm{C}$ for $10 \mathrm{~min}$ to gelatinize the starch slurry. The obtained gelatinized starch was cooled to $30 \pm 5^{\circ} \mathrm{C}$ and $\mathrm{GA}$ was added to obtain the following content on dry starch basis: $0.1,1.0$, 5.0 and $10.0 \mathrm{~g} / 100 \mathrm{~g}$. The mixtures were then homogenized by a magnetic stirring at $700 \mathrm{rpm}$ for $10 \mathrm{~min}$. The first part of the mixtures was freeze-dried in the FT33 laboratory dryer (Armfield, Ringwood, UK) for up to approximately $4 \mathrm{~g} / 100 \mathrm{~g}$ moisture content and ground in the KN 195 Knifetec laboratory mill (Foss, Hilleroed, Denmark). The second part of the mixtures was immediately fed to the Mini B-290 spray dryer (Buchi, Chadderton, Switzerland). The inlet and outlet air temperatures were maintained at $160 \pm 5^{\circ} \mathrm{C}$ and $75 \pm 5^{\circ} \mathrm{C}$, respectively. The collected powder was stored in three plastic bags (one inside another) at $4^{\circ} \mathrm{C}$. The whole experiment was repeated in three consecutive batches.

\section{Determination of the moisture content and water activity}

Prior to analysis, samples were stored overnight in the triple plastic bags at $4^{\circ} \mathrm{C}$. Moisture content of encapsulated GA was determined by a gravimetric method by oven drying at $105^{\circ} \mathrm{C}$ to a constant weight. Water activity was measured by using a LabSwift-aw portable water activity meter (Lachen, Switzerland).

\section{Determination of the encapsulation efficiency}

The ethanol-water-acetic acid mixture (42:50:8, v/v/v) was used as the extractant of gallic acid [Robert et al., 2010]. The prepared capsule powders $(0.50 \pm 0.02 \mathrm{~g})$ were washed with $5 \mathrm{~mL}$ of the solvent. Then supernatants were collected and GA content, removed from capsule surface (surface GA), was determined. To determine the total GA content, $0.50 \pm 0.02 \mathrm{~g}$ of the capsule powder was mixed with $5 \mathrm{~mL}$ of the extractant and placed in the ultrasonic bath YJ5120-1 (Baistra, Zhejiang, China) at $30^{\circ} \mathrm{C}$ for $30 \mathrm{~min}$ and filtered. 
Each supernatant $(200 \mu \mathrm{L})$, containing GA, was mixed with $1 \mathrm{~mL}$ of distilled water and $100 \mu \mathrm{L}$ of the Folin-Ciocalteu phenol reagent (previously diluted with distilled water 1:1, $\mathrm{v} / \mathrm{v})$. After $5 \mathrm{~min}, 2 \mathrm{~mL}$ of the water solution of sodium carbonate $(0.1 \mathrm{~g} / \mathrm{mL})$ was added and the mixture was allowed to stand at room temperature for $60 \mathrm{~min}$, and then was centrifuged at $2500 \times \mathrm{g}$ for $10 \mathrm{~min}$. The absorbance was measured at $725 \mathrm{~nm}$ by a Jenway 6300 spectrophotometer (Cole-Parmer, Stone, United Kingdom) [Jung et al., 2011].

Encapsulation efficiency (EE) was calculated as:

$$
\mathrm{EE}=100 \times(1-\text { Surface GA content/Total GA content })
$$

\section{Capsule (pellet) surface analysis}

Prior analysis, capsules surface was cleaned by degasation using the AD-9 Autosorb Degasser (Quantachrome Instruments, Boynton Beach, USA) at $25^{\circ} \mathrm{C}$ for $24 \mathrm{~h}$. Sample surface and pores were analyzed using a Quadrasorb SI gas sorption analysis system (Quantachrome Instrumentis, Boynton Beach, USA). Liquid nitrogen (at $-196^{\circ} \mathrm{C}$ ) was applied for the physical sorption-desorption isotherms. Sample surface was analyzed by Brunauer-Emmett-Teller (BET) method and t-method, pore volume and size distribution by Barrett-Joyner-Halenda (BJH) method, micropore volume and pore size by Dubinin-Radushkevich (DR) method [Quantachrome Instruments, 2013]. Acquired data was analyzed by using QuadraWin ${ }^{\mathrm{TM}}$ software that was supplied together with equipment.

\section{Microscopy}

Scanning electron microscopy (SEM) was performed by using the Mira/LMU electron microscope system (Tescan Brno, Kohoutovice, Czech Republic). Energy dispersive X-ray spectroscopy analysis by using the Inca Energy 350 spectrometer (Oxford Instruments, UK) was used to determine the capsule surface morphology. Secondary electron detector was equipped with a YAG $\left(\mathrm{Y}_{3} \mathrm{Al}_{5} \mathrm{O}_{12}\right)$ scintillation crystal and was functioning in the vacuum regime. Prior to analysis, the sample was coated with $20 \mathrm{~nm}$ thick gold layer to provide electrical conductivity.

\section{Statistical analysis}

RStudio software was used for statistical analysis and one-way ANOVA $(P \leq 0.05)$ was applied to determine the differences between GA encapsulation efficiencies, moisture content and surface analysis data. Tukey's range test was applied for mean value comparison.

\section{RESULTS AND DISCUSSION}

The efficiencies of GA encapsulation with low DE hydrolyzed potato starch as a wall material using FD and SD methods are presented in Figure 1. Statistical analysis showed no significant difference in efficiencies of processes carried out by both methods $(\mathrm{P}>0.05)$. However, Pasrija et al. [2015] reported that during encapsulation of green tea extract using maltodextrin (DE 19.2) and $\beta$-cyclodextrin (molecular weight: $1173 \mathrm{Da}$ ), the FD samples exhibited higher encapsulation efficiency (60-70\%) than the SD samples (40-69\%).

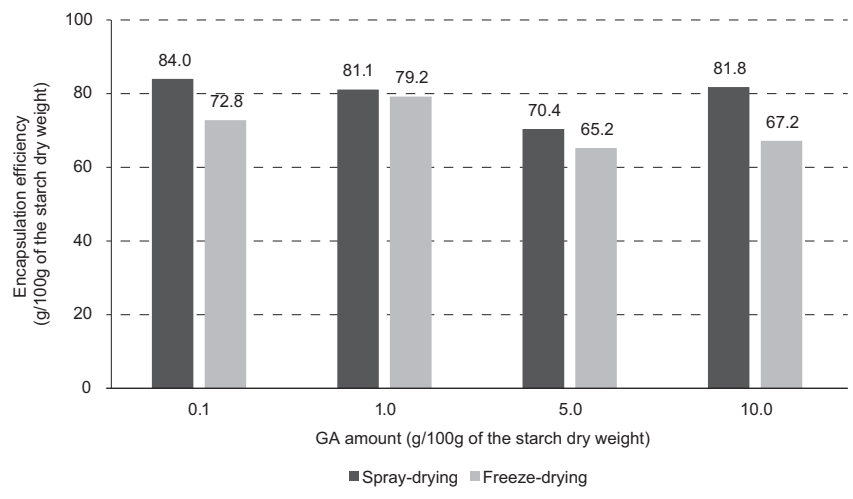

FIGURE 1. Gallic acid (GA) encapsulation efficiencies using spray-drying (SD) and freeze-drying (FD) techniques with low dextrose equivalent (DE 2) as a wall material.

Modified starch in the present study, acquired by acid hydrolysis with $3 \mathrm{~N}$ sulfuric acid, exhibited DE of approximately 2, which means very low or almost none reducing sugar content. Except DE, the type of starch chemical modification has a significant effect on rheological and functional properties [Pycia et al., 2016]. Studies of microencapsulation of the Averrhoa carambola pomace phenolic extract with maltodextrin $(\leq 20 \mathrm{DE})$ as a wall material showed that in both SD and FD capsules phenolic content in the core of the capsule increased with increase in the maltodextrin content [Saikia et al., 2015].

In the present study, it was possible to achieve encapsulation efficiency of $65-79 \%$ for the FD and $70-84 \%$ for SD samples. GA had been chosen as model water soluble phenolic compound. It was found that its relative solubility in solvents is as follows: $\mathrm{W}_{\text {methanol }}>\mathrm{W}_{\text {ethanol }}>\mathrm{W}_{\text {water }}$ [Daneshfar et $a l, 2008]$. As long chain polysaccharides are insoluble in alcohols, water had been chosen as a solvent. It is assumed that, after GA-starch solution homogenization prior to encapsulation, GA was evenly distributed in the mass. Because of that, the relationship between GA concentration on the capsule surface and in the core must be approximately the same, which leads to the similar encapsulation efficiencies of the samples with different GA-starch ratios.

The differences in the surface morphology are dependent on the encapsulation technique and the operation conditions and parameters. Visual appearance of the prepared SD and FD microcapsules can be observed in Figure 2. The SD samples had a spherical shape form due to the specifics of the spray-drying process as infeed liquid sample was atomized in the drying chamber. Due to the solvent surface tension, while falling through the chamber droplets formed round droplets that were dried by air forming spherical capsules. At the same time, the FD particles appeared in irregular shapeless forms. They were monolithic and varied highly in shape and size. The form and inner structure of the FD particles were also affected by the encapsulation process. As the whole liquid sample was rapidly frozen, GA was fixed in the wall material matrix. After freeze-drying, the matrix was crushed and, as a result, shapeless particles were produced. SD particles also varied in size and sometimes tended to stick together, making agglomerates. This fact can be explained by possible interactions between particles, such as static charge on the surface of the SD cap- 

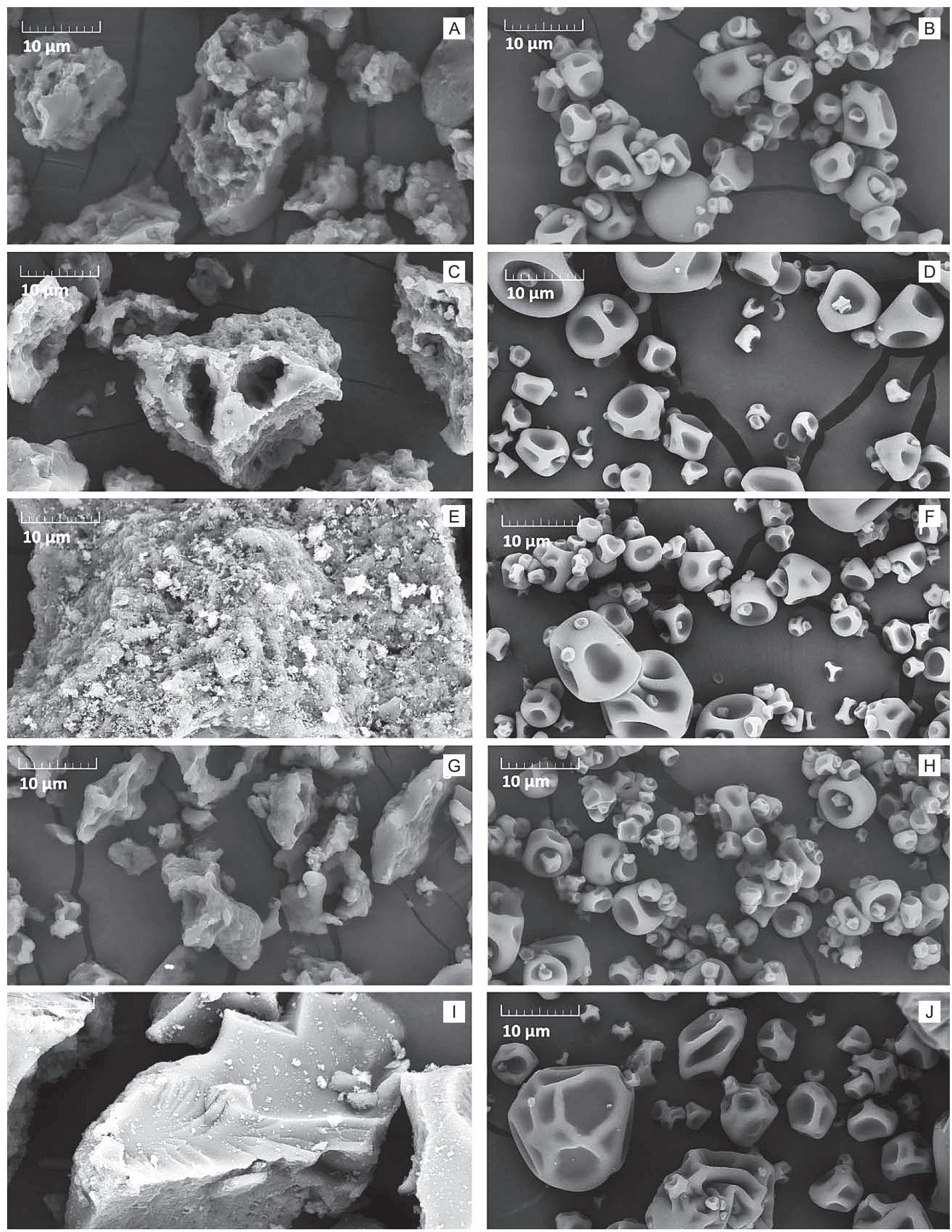

FIGURE 2. Encapsulation of gallic acid (GA) with acid-modified low dextrose equivalent potato starch under electron microscope; A, C, E, G and I freeze-dried samples with GA content of 0, 0.1, 1.0, 5.0 and $10.0 \mathrm{~g} / 100 \mathrm{~g}$ starch d.w., respectively; B, D, F, H and J - spray-dried samples with GA content of $0,0.1,1.0,5.0$ and $10.0 \mathrm{~g} / 100 \mathrm{~g}$ starch d.w., respectively. 
sules (that appeared during the drying process when capsules were moving in the air in the drying chamber of the spray dryer), by immobile and mobile liquid bridge developments, and possible mechanic interactions due to the shape cohesion [Boonyai et al., 2004]. In addition, the second stickiness process can be distinguished - stickiness of particles to wall surface of the dryer (adhesion) [Papadakis \& Bahu, 1992]. The second mentioned particle stickiness process usually causes irreversible powder losses, as the sample in the drying chamber is a subject to prolonged thermal treatment which can lead to the oxidation and degradation of sensitive compounds. It has been reported that at temperatures of $20^{\circ} \mathrm{C}$ above the glass transition temperature $(\mathrm{Tg})$, maltodextrin particles undergo transition from glassy to rubbery state forming soft sticky particles [Du et al., 2014]. As the particle surface energy increases, molecules become very sticky, start to interact with low energy solid surfaces (glass walls of the drying chamber), and stick to it [Bhandari \& Howes, 2005]. Taking in consideration that $\mathrm{Tg}$ of starch can vary from 75 to $90^{\circ} \mathrm{C}$, as reported by different authors [Jenkins \& Donald, 1998; Leszczynski, 1987], and that spray-drying outlet temperature in the current study did not exceed $80^{\circ} \mathrm{C}$, it could be assumed that, at the beginning, solidified particles stuck to the surface of the drying chamber due to the electrical charge. Being under constant heating by hot air at $160 \pm 5^{\circ} \mathrm{C}$, maltodextrin remained in the high energy state and was highly sticky. As a result, large amount of particles, that were flying in the drying chamber and came into contact with a sticky wall surface, were entrapped and formed additional irreversible losses. In addition, very fine SD particle could bypass an air filter and also be considered as losses. Although, the extent of losses due to adhesion depends not only on the spray-dried material properties, but also on the drying parameters, that should be adjusted for each product, and overall dryer construction.

Differences were observed in the moisture content and water activities of FD and SD samples (Table 1), the values of which were completely dependent on the drying method.
TABLE 1. Moisture content $(\mathrm{g} / 100 \mathrm{~g})$ and water activity $\left(\mathrm{a}_{\mathrm{w}}\right)$ of the prepared microcapsules.

\begin{tabular}{l|c|c|c|c}
\hline \multirow{2}{*}{$\begin{array}{l}\text { GA content } \\
(\mathrm{g} / 100 \mathrm{~g} \\
\text { starch d.w. })\end{array}$} & \multicolumn{2}{|c|}{ Moisture content } & \multicolumn{2}{c}{ Water activity } \\
\cline { 2 - 5 } & $\begin{array}{c}\mathrm{SD} \\
\text { samples }\end{array}$ & $\begin{array}{c}\text { FD } \\
\text { samples }\end{array}$ & SD samples & FD samples \\
\hline- & $4.8 \pm 0.2^{\mathrm{aA}}$ & $3.9 \pm 0.2^{\mathrm{bA}}$ & $0.172 \pm 0.017^{\mathrm{aA}}$ & $0.090 \pm 0.001^{\mathrm{bA}}$ \\
0.1 & $4.4 \pm 1.4^{\mathrm{aA}}$ & $3.8 \pm 1.5^{\mathrm{aA}}$ & $0.186 \pm 0.004^{\mathrm{aA}}$ & $0.064 \pm 0.004^{\mathrm{bB}}$ \\
1.0 & $4.9 \pm 1.3^{\mathrm{aA}}$ & $4.2 \pm 1.7^{\mathrm{aA}}$ & $0.187 \pm 0.007^{\mathrm{aA}}$ & $0.059 \pm 0.002^{\mathrm{bB}}$ \\
5.0 & $3.7 \pm 0.4^{\mathrm{aA}}$ & $3.2 \pm 0.4^{\mathrm{aA}}$ & $0.170 \pm 0.008^{\mathrm{aA}}$ & $0.076 \pm 0.014^{\mathrm{bA}}$ \\
10.0 & $5.0 \pm 1.8^{\mathrm{aA}}$ & $4.3 \pm 2.4^{\mathrm{aA}}$ & $0.174 \pm 0.016^{\mathrm{aA}}$ & $0.087 \pm 0.005^{\mathrm{bA}}$ \\
\hline
\end{tabular}

GA - gallic acid; SD - spray-dried; FD - freeze-dried. The data is presented as a mean $(n=3) \pm$ standard deviation. Similar lowercase letters indicate no significant difference among values in rows $(P>0.05)$; similar uppercase letters indicate no significant difference among values in columns $(\mathrm{P}>0.05)$.

The FD samples showed much lower $\mathrm{a}_{\mathrm{w}}$ values (0.059-0.090, with an average moisture content of $3.86 \pm 1.25 \mathrm{~g} / 100 \mathrm{~g}$ ) than the SD samples $(0.170-0.187$, with an average moisture content of $4.57 \pm 1.02 \mathrm{~g} / 100 \mathrm{~g}$ ), which means that moisture in the SD capsules is more accessible and could complicate capsule handling. Moisture content of SD and FD samples differed significantly $(P<0.05)$. A slightly higher moisture content of the SD samples could be due to the higher relative air humidity in the room during the spray-drying process, because moisture transfer rate from the samples in the dryer to the surrounding air was much more impetuous than during the freeze-drying process.

It was reported that low DE starch hydrolysates tended to form quite porous structures, that in the case of flavor compounds can lead to oxygen penetration through the barrier. Incorporation of the low molecular weight carbohydrates (glucose, sucrose, maltose or higher DE hydrolyzed starches)

TABLE 2. Capsule surface analysis by Brunauer-Emmett-Teller (BET) method and t-method.

\begin{tabular}{|c|c|c|c|c|c|c|}
\hline \multirow[b]{2}{*}{ Encap. method } & \multirow{2}{*}{$\begin{array}{l}\text { GA content } \\
(\mathrm{g} / 100 \mathrm{~g} \\
\text { starch d.w. })\end{array}$} & \multirow[b]{2}{*}{$\begin{array}{l}\text { BET surface area } \\
\qquad\left(\mathrm{m}^{2} / \mathrm{g}\right)\end{array}$} & \multicolumn{3}{|c|}{ t-method } & \multirow{2}{*}{$\begin{array}{l}\text { Average pore } \\
\text { diameter } \\
(\mathrm{nm})\end{array}$} \\
\hline & & & $\begin{array}{c}\text { External surface } \\
\text { area } \\
\left(\mathrm{m}^{2} / \mathrm{g}\right) \\
\end{array}$ & $\begin{array}{l}\text { MP surface area } \\
\qquad\left(\mathrm{m}^{2} / \mathrm{g}\right)\end{array}$ & $\begin{array}{l}\text { MP volume } \\
\left(\mathrm{cm}^{3} / \mathrm{g}\right)\end{array}$ & \\
\hline \multirow{5}{*}{ SD } & - & 1.231 & 1.112 & 0.119 & $1.7 \times 10^{-4}$ & 9.01 \\
\hline & 0.1 & 0.853 & 0.663 & 0.190 & $1.8 \times 10^{-4}$ & 7.31 \\
\hline & 1.0 & 1.436 & 1.283 & 0.152 & $0.2 \times 10^{-4}$ & 10.42 \\
\hline & 5.0 & 1.897 & 1.529 & 0.367 & $5.8 \times 10^{-4}$ & 7.39 \\
\hline & 10.0 & 1.482 & 1.482 & 0 & 0 & 14.76 \\
\hline \multirow{5}{*}{ FD } & - & 0.766 & 0.767 & 0 & 0 & 15.26 \\
\hline & 0.1 & 1.417 & 1.417 & 0 & 0 & 28.49 \\
\hline & 1.0 & 1.293 & 1.293 & 0 & 0 & 30.32 \\
\hline & 5.0 & 1.825 & 1.662 & 0.162 & $4.4 \times 10^{-4}$ & 8.92 \\
\hline & 10.0 & 1.125 & 1.125 & 0 & 0 & 9.64 \\
\hline
\end{tabular}

GA - gallic acid; MP - micropore; SD - spray-drying; FD - freeze-drying. 
TABLE 3. Capsule surface analysis by Barrett-Joyner-Halenda (BJH) and Dubinin-Radushkevich (DR) methods.

\begin{tabular}{|c|c|c|c|c|c|c|c|}
\hline \multirow[b]{2}{*}{ Encap. method } & \multirow[b]{2}{*}{$\begin{array}{l}\text { GA content } \\
\text { (g/100 g } \\
\text { starch d.w.) }\end{array}$} & \multicolumn{3}{|c|}{ BJH method } & \multicolumn{3}{|c|}{ DR method } \\
\hline & & $\begin{array}{c}\begin{array}{c}\text { Cumulative } \\
\text { desorption } \\
\text { surface area } \\
\left(\mathrm{m}^{2} / \mathrm{g}\right)\end{array} \\
\end{array}$ & $\begin{array}{c}\text { Cumulative } \\
\text { desorption pore } \\
\text { volume } \\
\left(\mathrm{cm}^{3} / \mathrm{g}\right) \\
\end{array}$ & $\begin{array}{l}\text { Desorption pore } \\
\text { diameter } \\
(\mathrm{nm})\end{array}$ & $\begin{array}{c}\text { MP area } \\
\left(\mathrm{m}^{2} / \mathrm{g}\right)\end{array}$ & $\begin{array}{l}\text { MP volume } \\
\left(\mathrm{cm}^{3} / \mathrm{g}\right)\end{array}$ & $\begin{array}{l}\text { MP pore width } \\
(\mathrm{nm})\end{array}$ \\
\hline \multirow{5}{*}{ SD } & - & 0.929 & $2.4 \times 10^{-3}$ & 3.115 & 1.533 & $5.5 \times 10^{-4}$ & 2.571 \\
\hline & 0.1 & 0.472 & $1.2 \times 10^{-3}$ & 4.417 & 1.108 & $3.9 \times 10^{-4}$ & 2.664 \\
\hline & 1.0 & 0.779 & $3.1 \times 10^{-3}$ & 3.105 & 2.116 & $7.5 \times 10^{-4}$ & 2.679 \\
\hline & 5.0 & 1.296 & $2.6 \times 10^{-3}$ & 3.573 & 2.374 & $8.4 \times 10^{-4}$ & 2.756 \\
\hline & 10.0 & 0.896 & $4.9 \times 10^{-3}$ & 3.205 & 2.032 & $7.2 \times 10^{-4}$ & 2.673 \\
\hline \multirow{5}{*}{ FD } & - & 0.632 & $2.7 \times 10^{-3}$ & 3.106 & 1.028 & $3.7 \times 10^{-4}$ & 2.677 \\
\hline & 0.1 & 1.053 & $9.5 \times 10^{-3}$ & 2.958 & 1.968 & $7.0 \times 10^{-4}$ & 2.682 \\
\hline & 1.0 & 1.021 & $9.3 \times 10^{-3}$ & 3.259 & 1.873 & $6.7 \times 10^{-4}$ & 2.891 \\
\hline & 5.0 & 1.225 & $3.1 \times 10^{-3}$ & 3.055 & 2.229 & $7.9 \times 10^{-4}$ & 2.843 \\
\hline & 10.0 & 1.122 & $2.4 \times 10^{-3}$ & 2.959 & 1.648 & $5.9 \times 10^{-4}$ & 2.915 \\
\hline
\end{tabular}

GA - gallic acid; MP - micropore; SD - spray-drying; FD - freeze-drying.

greatly improves solidity of the matrix structure [Reineccius \& Yan, 2016]. Thus, more porous structure could lead to the formation of larger surface area, decrease in surface to mass ratio, and, as a result, higher content of GA on the surface and lower encapsulation efficiency. This could explain the difference in the results with findings of other authors [Pasrija et al., 2015; Saikia et al., 2015] who reported higher encapsulation efficiency of the FD samples.

The results of surface analysis obtained by the BET method and t-method are shown in Table 2. The BET method is based on the measurement of the amount of physical multi-layer adsorption of non-corrosive gas (usually nitrogen) on solid materials [Brunauer et al., 1938]. Meanwhile, the t-method allows determining the micropore volume and surface area through comparison of a plotted isotherm of the microporous material with a standard Type II isotherm [De Boer et al., 1966]. The samples with 5\% GA content had the highest BET surface area in both types of samples $\left(1.897 \mathrm{~m}^{2} / \mathrm{g}\right.$ in SD samples and $1.825 \mathrm{~m}^{2} / \mathrm{g}$ in FD samples, respectively). Overall, both analyses did not show significant difference in the external surface area values. The SD samples had many micropores, that are mostly absent in the FD capsules. Average pore diameter was much larger in the FD samples.

Table 3 shows capsule surface analysis during nitrogen desorption (BJH method) and DR micropore analysis. The BJH method is based upon the Wheeler theory of combined physical adsorption and capillary condensation, and the assumption that pores have a cylindrical shape and that their radius is equal to the sum of Kelvin radius and the thickness of the film adsorbed on wall of the pore [Barrett et al., 1951]. The DR equation is based upon Polanyi and Goldmann's potential theory, an assumptions of a change in the potential energy between the gas and adsorbed phases and a characteristic energy of a given solid [Dubinin \& Radushkevich, 1947]. The FD samples showed larger cumulative desorption sur- face area (from 0.632 to $1.225 \mathrm{~m}^{2} / \mathrm{g}$ ) and higher cumulative desorption pore volumes (from $2.4 \times 10^{-3}$ to $9.5 \times 10^{-3} \mathrm{~cm}^{3} / \mathrm{g}$ ) than the SD samples (from $0.472 \times 10^{-3}$ to $1.296 \times 10^{-3} \mathrm{~cm}^{2} / \mathrm{g}$ and from $1.2 \times 10^{-3}$ to $4.9 \times 10^{-3} \mathrm{~cm}^{3} / \mathrm{g}$, respectively). The DR method showed micropore presence on the FD capsule surface with an average micropore surface area from 1.028 to $2.229 \mathrm{~m}^{2} / \mathrm{g}$, which was smaller than that of the SD samples (from 1.108 to $2.374 \mathrm{~m}^{2} / \mathrm{g}$ ), which resulted in the higher micropore volume in the SD samples. As mentioned previously, in the case of FD particle structure is formed mostly during the initial freezing process. Pore size is determined by the rate of temperature decrease during sample freezing before freeze-drying, as bigger ice crystals are formed at low freezing rates which after sublimation results in a bigger pore diameter and larger surface area, and vice versa - during rapid freezing, smaller ice crystals are formed. It is reported that samples prepared from maltodextrin and frozen at the freezing rate of 0.65 to $0.70^{\circ} \mathrm{C} / \mathrm{min}$ showed a higher initial content of encapsulated material than at lower freezing rates [Ramirez et al., 2015]. In addition, high pressure during FD can lead to the increase of shrinkage and decrease of porosity [Oikonomopoulou \& Krokida, 2012], but can result in even more expensive drying method as FD consists of four steps: freezing, vacuum, sublimation, and condensation with total energy consumption of approximately 4\%, 26\%, 25\%, and 45\% [Ratti, 2001]. As with the decreasing vacuum, the more energy will be required for sublimation. Although, the influence of FD rate on the formed capsules is highly dependent on the chosen encapsulation material and freezing rate does not affect capsules prepared from gum arabic (very good but expensive encapsulation material) [Ramirez et al., 2015].

Bigger porosity implies more rapid release and poorer protection of the encapsulated material as there will be larger contact area with the environment [Zuidam et al., 2009]. In general, polyphenols are considered thermostable com- 
pounds [Im et al., 2011], which makes SD a more suitable encapsulation technology. On the other hand, in the case of dealing with high-value thermo-sensitive raw material, FD is a great preservation method that is more economically efficient for long storage in comparison with freezing and storage at low temperature that require even greater energy consumption [Lorentzen, 1979].

\section{CONCLUSION}

Results of the present study did not show the significant difference in the encapsulation efficiency of the water-soluble gallic acid (GA) microencapsulated by freeze- and spray-drying methods using acid-hydrolyzed potato starch with low dextrose equivalent (DE 2) as a wall material. The main difference between the two mentioned microcapsule types was in the capsule shape/form and water activity values. The SD capsules were of the spherical shape, with a higher number of micropores, and had higher water activity values. The FD samples were shapeless, with larger size and higher number of pores, and lower water activity $\left(\mathrm{a}_{\mathrm{w}} 0.059-0.090\right)$. Although, higher pore volume (2.4-9.5 $\mathrm{m}^{3} / \mathrm{g}$ for FD and 1.2-4.9 $\mathrm{m}^{3} / \mathrm{g}$ for SD samples) and, as a result, larger surface area $\left(0.632-1.225 \mathrm{~m}^{2} / \mathrm{g}\right.$ for FD and 0.472 to $1.296 \mathrm{~m}^{2} / \mathrm{g}$ for SD samples) decreased a surface to volume ratio and, as a result, GA content on the surface of the FD samples. This could be considered as the loss because GA on the surface of the capsule is easily accessible to the hazardous outer environment factors. In literature, FD is often used for the development of new encapsulation methods for the food production field. Although, present study does not justify FD application over SD, if targeted core material is not a high value compound that exhibits instability at high temperatures, as particles produced by FD not only are much more expensive but also the process results in more losses due to the bigger pore sizes and, as a result, larger surface area.

The present work makes a basis for the future studies on the application of microencapsulated phenolics in food production.

\section{RESEARCH FUNDING}

The present study was supported by the Latvian State Research program Agricultural Resources for Sustainable Production of Qualitative and Healthy Foods in Latvia (AgroBioRes)' (2014-2017). Project No. 4 'Sustainable use of local agricultural resources for qualitative and healthy food product development (FOOD)'.

\section{CONFLICT OF INTEREST}

Authors declares that there is no conflict of interest.

\section{REFERENCES}

1. Barbosa M.I.M.J., Borsarelli C.D., Mercadante Z., Light stability of spray-dried bixin encapsulated with different edible polysaccharide preparations. Food. Res. Int., 2005, 38, 989-994.

2. Barrett E.P., Joyner L.G., Halenda P.P., The determination of pore volume and area distributions in porous substances.
I. Computations form nitrogen isotherms. J. Am. Chem. Soc., 1951, 73, 373-380.

3. Bhandari B., Howes T., Relating the stickiness property of foods undergoing drying and dried products to their surface energetics. Dry. Technol., 2005, 23, 781-797.

4. Boonyai P., Bhandri B., Howes T., Stickiness measurement techniques for food powders: a review. Powder Technol., 2004, 145, 34-46.

5. Brunauer S., Emmett P.H., Teller E., Adsorption of gases in multimolecular layers. J. Am. Chem. Soc., 1938, 60, 309-319.

6. Carneiro H.C.F.F., Tonon R.V., Grosso C.R.F.F., Hubinger M.D., Encapsulation efficiency and oxidative stability of flaxseed oil microencapsulated by spray drying using different combinations of wall materials. J. Food. Eng., 2013, 115, 443-451.

7. Daneshfar A., Ghaziaskar H.S., Homayoun N., Solubility of gallic acid in methanol, ethanol, water, and ethyl acetate. J. Chem. Eng. Data., 2008, 53, 776-778.

8. De Boer J.H., Lippens B.C., Linsen B.G., Broekhoff J.C.P., Van den Hauvel A., Osinga Th.J., The t-curve of multimolecular $\mathrm{N}_{2}$-adsorption. J. Colloid Interf. Sci., 1966, 21, 405-414.

9. Du J., Ge ZZ., Xu Z., Zou B., Zhang Y., Li C.M., Comparison of the efficiency of five different drying carriers on the spray drying of persimmon pulp powders. Dry. Technol., 2014, 32, 1157-1166.

10. Dubey R., Shami T.C., Bhasker Rao K.U., Microencapsulation technology and applications. Defence Sci. J., 2009, 59, 82-95.

11. Dubinin M.M., Radushkevich L.V., The equation of the characteristic curve of activated charcoal. Proc. Natl. Acad. Sci. USSR, 1947, 55, 331-333.

12. Flink J.M., Energy analysis in dehydration process. Food Technol., 1977, 31, 77-79.

13. Gibbs B.F., Kermasha S.A.I., Mulligan C.N., Encapsulation in the food industry: a review. Int. J. Food Sci. Nutr., 1999, 50, 213-224.

14. Im H.W., Park Y.-S., Leontowicz H., Leontowicz M., Namiesnik J., Ham K.-S., Kang S.-G., Najiman K., Gorinstein S., The thermostability, bioactive compounds and antioxidant activity of some vegetables subjected to different durations of boiling: investigation in vitro. LWT - Food Sci. Technol., 2011, 44, 92-99.

15. Im H.W., Suh B.S., Lee S.U., Kozukue N., Ohnisi-Kameyama M., Levin C.E., Friedman M., Analysis of phenolic compounds by high-performance liquid chromatography and liquid chromatography/mass spectrometry in potato plant flowers, leaves, stems, and tubers and in home-processed potatoes. J. Agr. Food. Chem., 2008, 56, 3341-3349.

16. Inglett G.E., Gelbman P., Reineccius G.A., Encapsulation of orange oil. Use of oligosaccharides from $\alpha$-amylase modified starches on maize, rice, cassava, and potato. 1988, in: ACS Symposium Series (eds. S.J. Risch, G.A. Reineccius). American Chemical Society, Washington, DC, pp. 30-36.

17. Jenkins P.J., Donald A.M., Gelatinisation of starch: a combined AXS/WAXS/DSC and SANS study. Carbohyd. Res., 1998, 308, 133-147.

18. Jung J.K., Lee S.U., Kozukue N., Levin C.E., Friedman M., Distribution of phenolic compounds and antioxidative activities in parts of sweet potato (Ipomoea batata L.) plants and in home processed roots. J. Food. Compos. Anal., 2011, 24, 29-37.

19. Kopelman I.J., Meydav S., Weinberg S., Storage studies of freeze dried lemon crystals. J. Food Technol., 1977, 12, 403-410. 
20. Lane J.H., Eynon L., Determination of reducing sugars by means of Fehling's solution with methylene blue as internal indicator. J. Soc. Chem. Ind. Trans., 1923, 32-36.

21. Leszczynski W., New methods for determination of starch gelatinization temperatures. Starch-Starke, 1987, 39, 375-378.

22. Loksuwan J., Characteristics of microencapsulated $\beta$-carotene formed by spray drying with modified tapioca starch, native tapioca starch and maltodextrin. Food Hydrocoll., 2007, 21(5-6), 928-935.

23. Loksuwan J., Process for producing modified starch used as encapsulating agents. Thailand, patent No 2146, 2005 (in Thai).

24. Lorentzen J., Quality and economics in freeze-drying. Chem. Ind., 1979, 14, 465-468.

25. Mulcahy E.M., Mulvihill D.M., O’Mahony J.A., Physicochemical properties of whey protein conjugated with starch hydrolysis products of different dextrose equivalent values. Int. Dairy. J., 2016, 53, 20-28.

26. Oikonomopoulou V.P., Krokida M.K., Structural proportion of dried potatoes, mushrooms, and strawberries as a function of freeze-drying pressure. Dry. Technol., 2012, 30, 351-361.

27. Papadakis S.E., Bahu R.E., The sticky issues of drying. Dry. Technol., 1992, 10, 817-837.

28. Pasrija D., Ezhilarasi P.N., Indrani D., Anandharamakrishnan C. Microencapsulation of green tea polyphenols and its effect on incorporated bread quality. LWT - Food Sci. Technol., 2015, 64, 289-296.

29. Poshadri A., Kuna A., Microencapsulation technology: A review. J. Res. ANGRAU, 2010, 38, 86-102.

30. Pourcel L., Routaboul J.M., Cheynier V., Lepiniec L., Debeaujon I., Flavonoid oxidation in plants: from biochemical properties to physiological functions. Trends Plant. Sci., 2007, 12, 29-36.

31. Pycia K., Juszczak L., Gałkowska D., Witczak M., Jaworska G., Maltodextrins from chemically modified starches. Selected physicochemical properties. Carbohyd. Polym., 2016, 146, 301-309.

32. Quantachrome Instruments. Quadrasorb EVOTM surface area \& pore size analyser, 2013, [https://quantachrome.com/pdf_brochures/evo_07160_brochure_revA.pdf].
33. Ramirez M.J., Giraldo G.I., Orrego C.E., Modeling and stability of polyphenol in spray-dried and freeze-dried fruit encapsulation. Powder Technol., 2015, 277, 89-96.

34. Ratti C., Hot air and freeze-drying of high-value foods: a review. J. Food. Eng., 2001, 49, 311-319.

35. Reineccius G.A., Flavor Encapsulation. Food. Rev. Int., 1989, 5, 147-176.

36. Reineccius G.A., Yan. C., Factors controlling the deterioration of spraydried flavourings and unsaturated lipids. Flavour. Frag. J., 2016, 31, 5-21.

37. Robert P., Gorena T., Romeo N., Sepulveda E., Chavez J., Saenz C., Encapsulation of polyphenols and anthocyanins from pomegranate (Punica granatum) by spray drying. Int. J. Food. Sci. Technol., 2010, 45, 1386-1494.

38. Saikia S., Mahnot N.K., Mahanta C.L., Optimisation of phenolic extraction from Averrhoa carambola pomace by response surface methodology and its microencapsulation by spray and freeze drying. Food. Chem., 2015, 171, 144-152.

39. Shahidi F., Han X.Q. Encapsulation of food ingredients. Crit. Rev. Food Sci. Nutr., 1993, 33, 501-547.

40. Singh N., Kamath V., Narasimhamurthy K., Rajini P.S., Protective effect of potato peel extract against carbon tetrachlorideinduced liver injury in rats. Environ. Toxicol. Pharmacol., 2008, 26, 241-246.

41. Varavinit S., Chaokasem N., Shobsngob S., Studies of flavor encapsulation by agents produced from modified sago and tapioca starches. Starch-Starke, 2001, 53, 281-287.

42. Zuidam N.J. Shimoni E., Overview of microencapsulates for use in food products or processes and methods to make them. 2009, in: Encapsulation Technologies for Food Active Ingredients and Food Processing (eds. N.J. Zuidam, V.A. Nedovic). Springer, Dordrecht, The Netherlands, pp. 3-31.

Submitted: 4 February 2017. Revised: 27 June and 3 December 2017. Accepted: 14 December 2017. Published on-line: 23 February 2018. 